\title{
Early and late changes in the respiratory system related to primary tuberculosis
}

\author{
T. G. VIL L A R \\ From the Department of Medicine, Lisbon University Hospital, Lisbon, Portugal
}

For 15 years Schwartz (1948) has been pointing out the importance of the tracheobronchial lymph nodes in the life cycle of tuberculous infection. However, only lately has the interest in this problem become more general.

Tuberculosis of the tracheobronchial lymph nodes may have serious end results because of the intimate relation of these nodes to the bronchial tree and the damage such tuberculous nodes could cause to the airways. Fig. 1 shows the relation of the tracheobronchial lymph nodes to the bronchial tree and the location of the related tuberculous bronchial lesions as seen in our patients (Villar, 1959).

In Fig. 2 I have summarized the life history of primary tuberculosis with especial reference to the

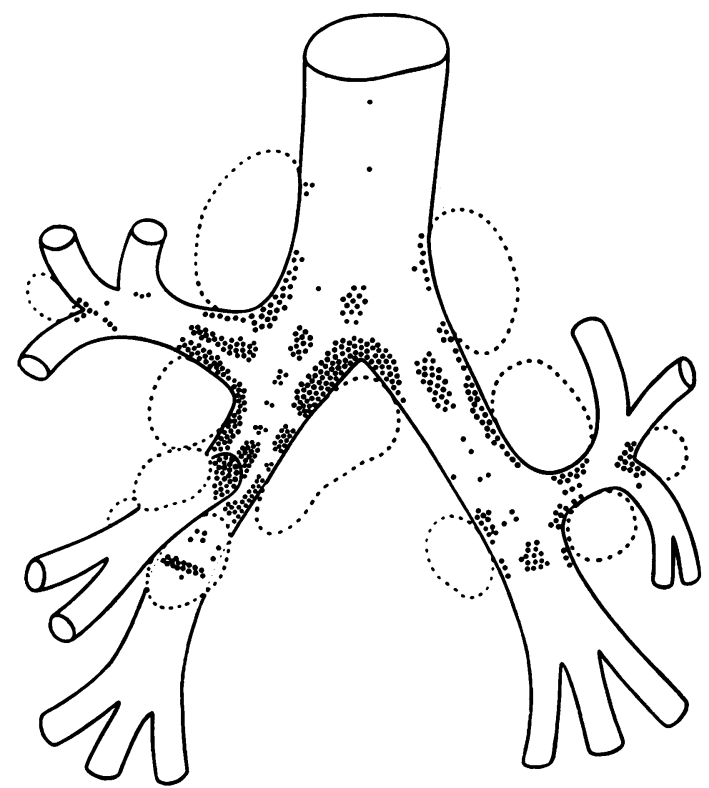

FIG. 1. Diagram showing the relation of the most important tracheobronchial lymph nodes to the bronchial tree and the localization of bronchial lesions. Each dot represents a lesion seen by me at bronchoscopy. tracheobronchial nodes and the bronchial lesionsi they may cause. A study of these patients suggestsin that this cycle may last from 10 to 50 years.

A tuberculous lymph node enlarges, adheres to응 a nearby bronchus through periadenitis, presses on the bronchial wall which it specifically infects $D$ causes local circulatory changes, and finally breaks? through into the bronchial lumen producing a sinus? or an ulcer. Around the sinus specific or non-0 specific granulation tissue may grow into the bronchus and form a granuloma. Sometimes theo lymph node itself will herniate into the bronchiak lumen. When there is extensive damage to the bronchial wall, healing may leave a cicatriciaf stenosis. At other times healing of the remains of the tuberculous lymph node may result in calcifica tion, and the calcified mass may later break迎 through the bronchial wall causing a so-called broncholith. When the destructive process is? localized, all that remains is a scar in the bronchial wall which may undergo malignant transformation Fortunately, however, on most occasions the bronchial wall returns almost completely toे normal. A healed tuberculous lymph node, whethen or not it once ruptured into the bronchus, may reactivate at any time and give rise to symptoms 3

This residual tuberculous pathology, both in thei nodes and in the bronchial wall, may produces certain clinical syndromes in any phase of its evolution. Asthma-like syndromes may be caused by reduction of the bronchial lumen due tof compression by the nodes, intrabronchial. granulomas, or cicatricial stenosis. Unexplainedo fever syndromes may be due to tuberculous activity in the lymph-node component of primary infection or to its reactivation at a later date. Unexplained ${ }^{\omega}$ haemoptysis may occur when the lymph nodo breaks into the bronchus during primary infection when reactivation takes place, or during the passage of a broncholith through the bronchiaf wall. The same conditions can cause unexplained positive sputum, and probably the so-callect primary bronchial tuberculosis can be explained? by this mechanism. 


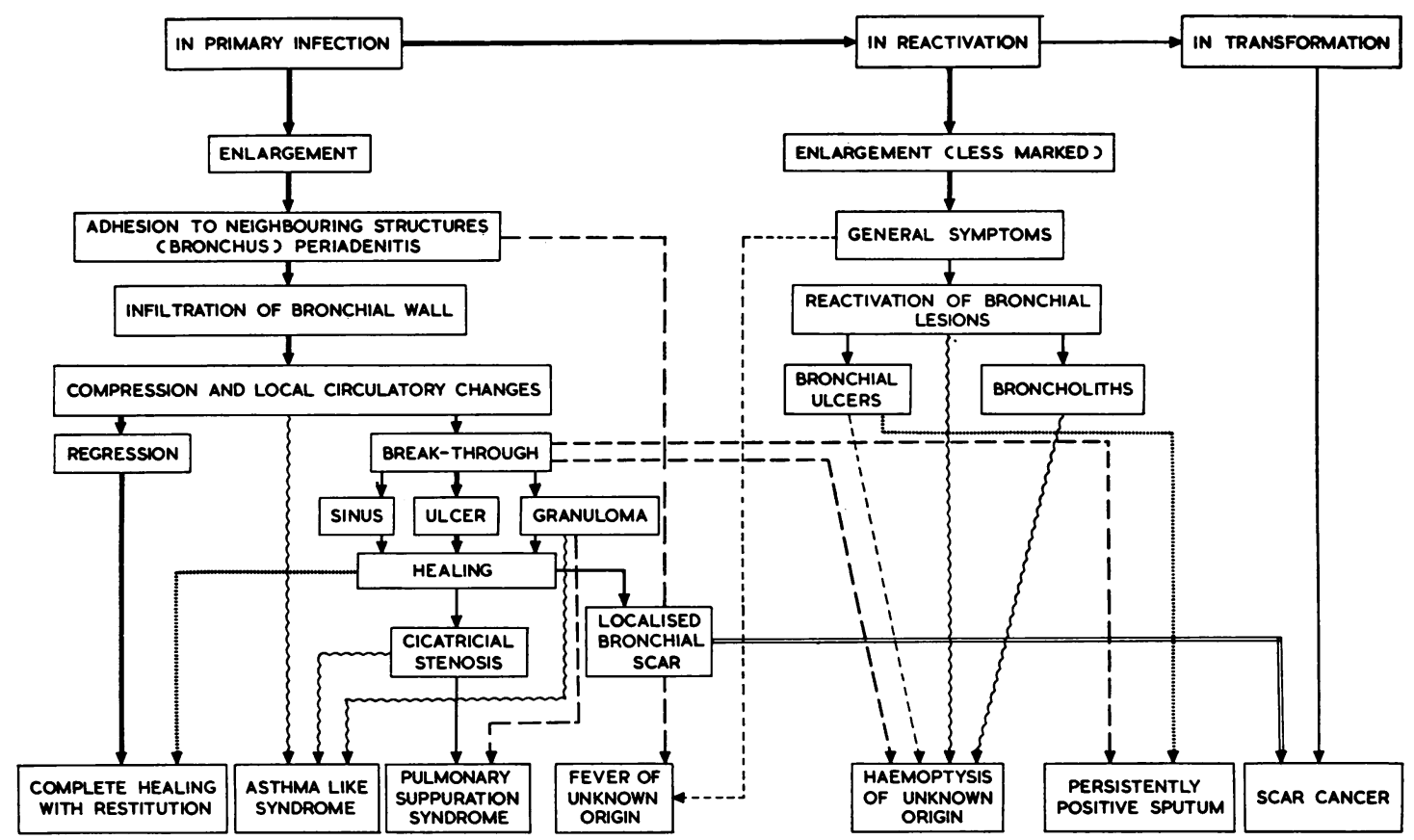

FIG. 2. Changes in tuberculous tracheobronchial lymph nodes and related bronchial lesions.

\section{MATERIAL AND METHODS}

Some of the problems of bronchial lymph-node tuberculosis have been studied by going over the case histories of nearly 5,000 tuberculous patients whom I have examined clinically, radiologically, and bronchoscopically within the last 13 years. Of these, 415 were children under 12 years of age. The remainder were from this age up to 70 years.

It was possible to follow the course of the bronchial and parenchymal lesions in 298 patients over periods of from six months to 12 years, and to try to relate this course to three different types of treatment: bed rest alone; chemotherapy using streptomycin as the main drug; and chemotherapy with isoniazid as the principal drug.

The incidence of the various types of bronchial lesions in the different age groups was analysed, the most important bronchial lesion being considered for this purpose in patients who had multiple lesions.

An attempt was made to correlate the pathology found with the clinical syndromes presented by the patients. For this purpose I studied not only those patients under my direct care but patients from the departments of paediatrics and infectious diseases of the Lisbon University Hospital.

\section{RESULTS}

Table I shows that the incidence of bronchial lesions in tuberculous children is very high (90\%).
The younger the child at the time of primary infection the higher the incidence of bronchial lesions. These findings agree with those of Macpherson, Zorab, and Reid (1960) in their smaller series of cases. This is particularly true of the bronchial lesions directly related to tuberculous tracheobronchial lymph nodes: compression, ulcers, fistulae, and granulomas. Quite probably, many of the cases classified as not being related to lymph-node involvement were in reality due to this type of pathology, only it was not possible to demonstrate this satisfactorily. However, most of these 'unrelated' cases were found in adults.

The course of the bronchial lesions followed from six months to 12 years is summarized in Table II. About half the infiltrative lesions led to an organized stenosis of the bronchus, and only one third resulted in complete cure. When extrinsic compression of the bronchus was recognized when the patient was first seen, the chances of complete cure were approximately $50 \%$, but a higher incidence of permanent damage was also noted. When a patient had bronchial ulcers or fistulae the chances of a complete cure of the bronchial lesions were about one third, while in $50 \%$ of the patients residual changes were found in the bronchi. Of the patients with granulomas, only one fourth returned to normal. As was to be expected, 
T A B LE I

\begin{tabular}{|c|c|c|c|c|c|c|c|c|c|c|c|c|}
\hline \multicolumn{13}{|c|}{ BRONCHIAL LESIONS FOUND IN 4.982 TUBERCULOUS PATIENTS } \\
\hline \multicolumn{2}{|c|}{ AGES } & $0-1$ & $2-5$ & $6-8$ & 9-12 & $13-15$ & $16-20$ & $21-30$ & $31-40$ & $41-50$ & $51-60$ & $61-70$ \\
\hline \multicolumn{2}{|c|}{ NO BRONCHIAL LESIONS } & 4 & 9 & 5 & 23 & $\sqrt{1}$ & 27 & 4 & $\mathbb{1}$ & 1 & $2 \pi$ & $\operatorname{la}^{6}$ \\
\hline \multirow{7}{*}{$\begin{array}{c}\text { BRONCHIAL } \\
\text { LESIONS } \\
\text { APPARENTLY } \\
\text { RELATED } \\
\text { TO } \\
\text { LYMPH-NODE } \\
\text { TUBERCULOSIS } \\
(700 \text { CASES })\end{array}$} & imf ILtration & 5 & 7 & 4 & 10 & 2 & 4 & 5 & 9 & 1 & 1 & - \\
\hline & COMPRESSION & 3 & 48 & 19 & 10 & 4 & 2 & 2 & 5 & 1 & 3 & 1 \\
\hline & ULCERS-FISTULAE & 11 & 36 & 17 & 27 & 14 & 29 & 76 & 24 & 12 & 2 & 3 \\
\hline & graHULOMAS & 1 & 18 & 15 & 6 & 9 & 14 & 17 & 8 & 4 & 3 & 2 \\
\hline & STENOSIS & - & 16 & 11 & 19 & 4 & 8 & 15 & 7 & 4 & 2 & 2 \\
\hline & SCARS & - & - & 1 & 2 & 2 & 12 & 23 & 9 & 5 & 7 & 6 \\
\hline & BRONCHOLITHS & - & 1 & - & - & - & 2 & 4 & - & 1 & - & - \\
\hline \multirow{4}{*}{$\begin{array}{c}\text { BRONCHIAL } \\
\text { LESIONS } \\
\text { APPARENTLY } \\
\text { NOT } \\
\text { RELATED } \\
\text { TO } \\
\text { LYMPH NODES } \\
\text { ( } 3031 \text { (ASES) } \\
\end{array}$} & imfiltration & 1 & 2 & 9 & 18 & 56 & 3 & $\$ 20$ & $2+2$ & 77 & 20 & 6 \\
\hline & ULCERS & - & - & - & 3 & 30 & 120 & 318 & 176 & 43 & 13 & 2 \\
\hline & GRANULOMAS & - & - & - & 2 & 6 & 16 & 62 & 28 & 10 & 4 & 2 \\
\hline & STENOSIS & - & - & 4 & 5 & 38 & 108 & $4^{33}$ & 21 & $\frac{71}{\pi}$ & 15 & 5 \\
\hline \multicolumn{2}{|c|}{ TOTALS } & 68 & 137 & 85 & 125 & 228 & 941 & 2.016 & $\$ 20$ & 325 & 102 & 35 \\
\hline
\end{tabular}

The shading represents the percentage of each type of lesion in each age group. It also emphasizes the variation in the incidence of tha type of lesion throughout the life span from 0 to 70 . In patients with more than one lesion, only the most important one is recorded.

T A B LE I I

COURSE OF BRONCHIAL LESIONS DUE TO TUBERCULOUS LYMPH NODES FOLLOWED FROM 6 MONTHS T 12 YEARS IN 204 PATIENTS Type of Lesion
when Last Seen Type of Lesion when First Seen

\begin{tabular}{ll}
\hline Infiltrative & Compression \\
Lesion & (27 Cases) \\
(9 Cases) &
\end{tabular}

Ulcer and
Fistula
(103 Cases)

Complete healing

Localized scar

Cicatricial stenosis

Functional stenosis

Still active or no change

$\begin{array}{cc}3 & 14 \\ 1 & 2 \\ 4 & 6 \\ -1 & 3 \\ \text { (2 years) } & 2 \\ \end{array}$

(103 Cases)

\begin{tabular}{c}
$\begin{array}{c}\text { Granuloma } \\
\text { (40 Cases) }\end{array}$ \\
\hline 10 \\
10 \\
13 \\
$\frac{7}{7}$ \\
(6 months \\
to 2 years)
\end{tabular}

38
26
$\frac{21}{18}$
(6 months
to 5 years)

no appreciable change was noted in the bronchial lesions of patients with cicatricial stenosis or bronchial scars.

From the analysis of these patients it seemed that the chances of a complete cure of active tuberculous bronchial lesions due to tuberculous lymph nodes were very much the same whatever the type of lesion, and that they occurred in between one third and one fourth of all patients.

The remainder finished up with residual bronchial pathology that might give rise to clinical syndromes at a later date. Table III shows the mosE frequent of these syndromes and the number of cases of each found in this series.

DYSPNOEIC SYNDROMES This type of syndrome characterized essentially by shortness of breath was found in 43 children and in 17 adults.

In 27 of the children there was shortness o $\vec{Q}$ breath, generally accompanied by wheezing an $₫$ sometimes by a whoop-like cough. The average ag霡 of these children was 4 years, with a minimumo 
T A B LE III

VARIOUS SYNDROMES DUE TO TUBERCULOUS MEDIASTINAL LYMPH NODES (298 CASES)

\begin{tabular}{llll}
$\begin{array}{l}\text { Due to } \\
\text { Active or }\end{array}$ & $\begin{array}{l}\text { Due to } \\
\text { Calcified }\end{array}$ & Surgery & (33 Cases) \\
\cline { 2 - 3 } Reacti- & Lymph & Lobec- & Pneumon- \\
vated & Nodes & tomy & ectomy \\
Lymph & (65 & (18 & (15 \\
Nodes & Cases) & Cases) & Cases) \\
(233 Cases) & &
\end{tabular}

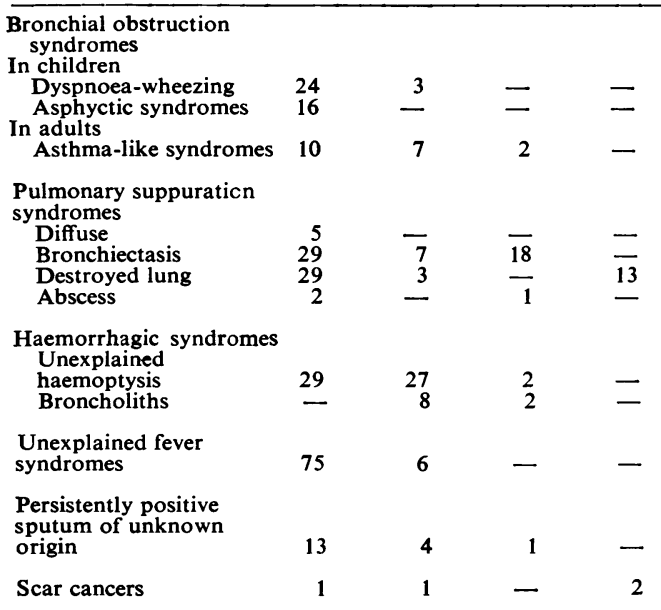

of six months and a maximum of 12 years. At bronchoscopy extrinsic compression was found in 12 patients, bronchial ulcers in four, granulomas in eight, organized stenosis in two, and bronchial scars in one. In three the changes were due to calcified lymph nodes.

Fig. 3 is a bronchogram of a 4-year-old child who presented this type of syndrome. It shows a granuloma at the entrance to the right lower lobe bronchus. When this was removed bronchoscopically the child became asymptomatic.

Sixteen children had serious attacks of suffocation that required emergency treatment (Villar, 1957). All were under 4 years of age and 11 were less than 1 year old. Those over 1 year all had endobronchial granulomas that had to be removed bronchoscopically. In one, there was a sudden breakthrough of a tuberculous lymph node into the bronchial tree, and it was necessary to remove the pathological tissue from the bronchus to save the child's life. Of those under 1 year old, only two had granulomas within the bronchus. All the others showed compression of the trachea or main bronchi, with or without ulceration. I was impressed by the fact that the severity of the symptoms of asphyxia and the degree of bronchial obstruction found at bronchoscopy did not always agree. The following is an example of this type of pathology:

R. L. C., a 2-year-old girl from an environment highly infected with tuberculosis, was admittted to the paediatric department of the University Hospital with noisy breathing, dyspnoea, and signs of rapidly progressing bronchial obstruction. A chest radiograph showed a radio-opacity of the whole of the left lung with obstructive emphysema of the right lung (Fig. 4). Emergency bronchoscopy showed a smooth, lobulated, polyp-like formation completely blocking the left main bronchus and a similar formation partially filling the right main bronchus but leaving a small crescent of lumen during inspiration (Fig. 5). The endobronchial tissue was removed from both bronchi with bronchoscopic forceps, and the bronchi were swabbed with adrenaline solution. Immediately after bronchoscopy the child breathed better, but after a while respiratory distress returned and she had to be placed in an oxygen tent. The dyspnoea subsided slowly, and gradually the patient improved on intensive isoniazid (INH) treatment. On discharge her chest film was almost normal (Fig. 6) and she has remained well for more than four years.

'Asthma' was diagnosed in 17 adults between the ages of 21 and 64 years, average age 35 years. The following changes were found in the bronchi of these patients : infiltration of the bronchial wall with positive sputum, 1 ; localized haemorrhagic bronchitis, 2 ; bronchial ulcers, 3 ; granulomas, 2 ; cicatricial stenosis, 4 ; and localized bronchial scars, 5. In seven of these patients the bronchial pathology was due to calcified lymph nodes, and bronchostenosis made lobectomy necessary in two patients.

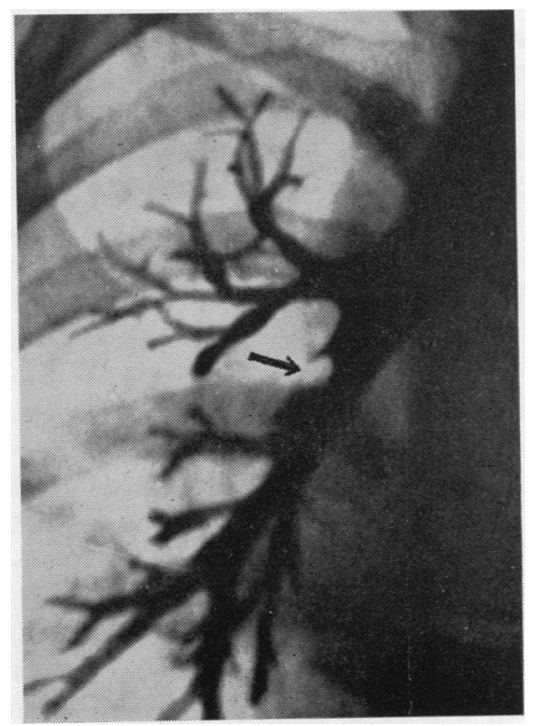

FIG. 3. Bronchogram showing an intrabronchial granuloma in a 4-year-old child. 

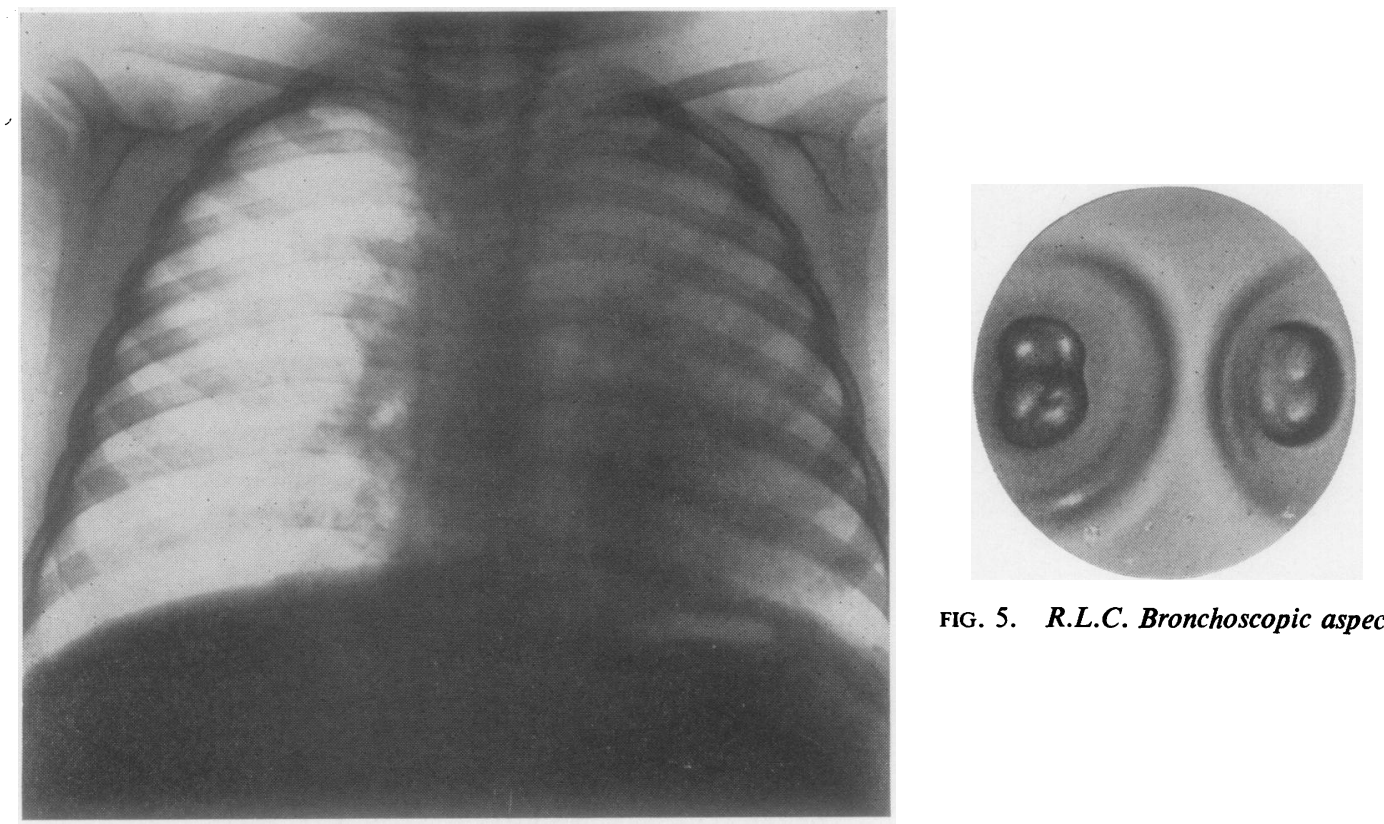

FIG. 5. R.L.C. Bronchoscopic aspect.

FIG. 4. R.L.C. Chest radiograph on admission showing opacity in the left lung and obstructive emphysema of the right lung.

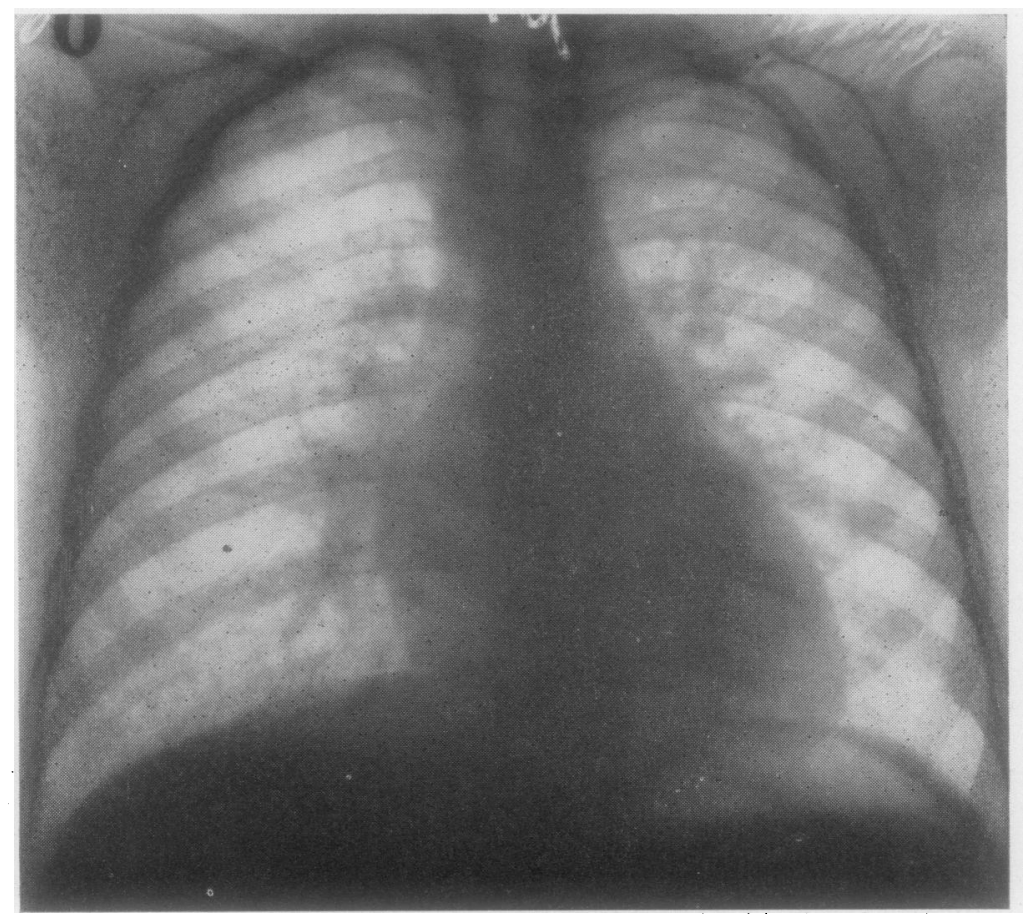

FIG. 6. R.L.C. Chest radiograph on discharge. 
PULMONARY SUPPURATION SYNDROMES Five patients with diffuse suppuration associated with active tuberculous mediastinal lymph nodes were seen, two children and three young adults.

Lobar bronchiectasis was found in 36 patients, 29 related to active or reactivated tuberculous mediastinal lymph nodes and seven to calcified nodes. Nineteen of the patients were children and 17 were adults; the calcified lymph nodes were equally distributed between the two groups. Among the children, bronchoscopy showed organized bronchostenosis in seven, granulomas in three, ulcers in two, and extrinsic compression in another two. In the remaining five, only signs of broncho-pulmonary suppuration were seen, and the narrowing of the bronchial lumen no longer existed. This shows that even though the bronchial obstruction may resolve, bronchiectasis can result if the obstruction lasts long enough. In the adult patients bronchoscopy showed organized stenosis in 15, endobronchial granuloma in one, and extrinsic compression in a 13-year-old boy. In 10 patients the upper lobes were involved, but in all others the pathology was located in the lower and middle lobes. Lobectomy was necessary in 18, all of whom presented organized bronchial stenosis, but was refused by eight patients. Six of the patients in whom resection was done were children.

'Destroyed lung', or bronchiectasis of the bronchial system of a whole lung, was seen in 32 patients, 20 children and 12 adults. In 25 the left lung was involved, and in three a calcified lymph node seemed responsible for the pathology. In all cases obstruction of one of the main bronchi was found on bronchoscopy, and Fig. 7 shows the bronchoscopic course of one such patient. In the adults, obstruction was caused by cicatricial stenosis in all except two in whom endobronchial granulomas were found. In the children, cicatricial stenosis was seen in nine patients, functional stenosis through weakening of the bronchial wall in two, extrinsic compression in three, endobronchial granulomas in four, and vegetating ulcers in two. In 13 patients a pneumonectomy was done.

Only in two patients could clinical lung abscesses be proved to be related to tuberculous lymph nodes, and in both an organized bronchial stenosis was found. In one patient a lobectomy was done.

A. D. D., a 56-year-old man, was admitted to the Medical Service of Lisbon University Hospital in July 1955 complaining of a dry cough of two months' duration, and weakness. A few days later he developed a severe pain in the right chest, and three weeks later he coughed up a large amount of purulent, foulsmelling sputum. The patient looked an aged emaciated man with gross clubbing of the fingers and toes; crackling sounds were heard at the base of the right lung posteriorly. A chest film on admission (Fig. 8) showed a large, flattened, thin-walled cavity in the right lower lobe. On bronchoscopy a fibrostenosis of the right lower lobe bronchus was seen, through which abundant purulent secretions bubbled. A bacteriological study of these secretions revealed a varied saprophytic flora, but no tubercle bacilli could be identified by direct smear or on culture. As the patient did not improve on medical treatment, he had a lobectomy performed in August 1955 for a pre-operative diagnosis of lower lobe lung abscess.

Examination of the resected lobe showed stenosis of the right lower lobe bronchus with abundant fibrous tissue and a large anthracotic scar: the cavity proved to be tuberculous.

HAEMORRHAGIC SYNDROMES: UNEXPLAINED HAEMOPTYSIS In 29 patients haemoptyses were found to be related to active or reactivated tracheobronchial lymph nodes. Only two of these patients were
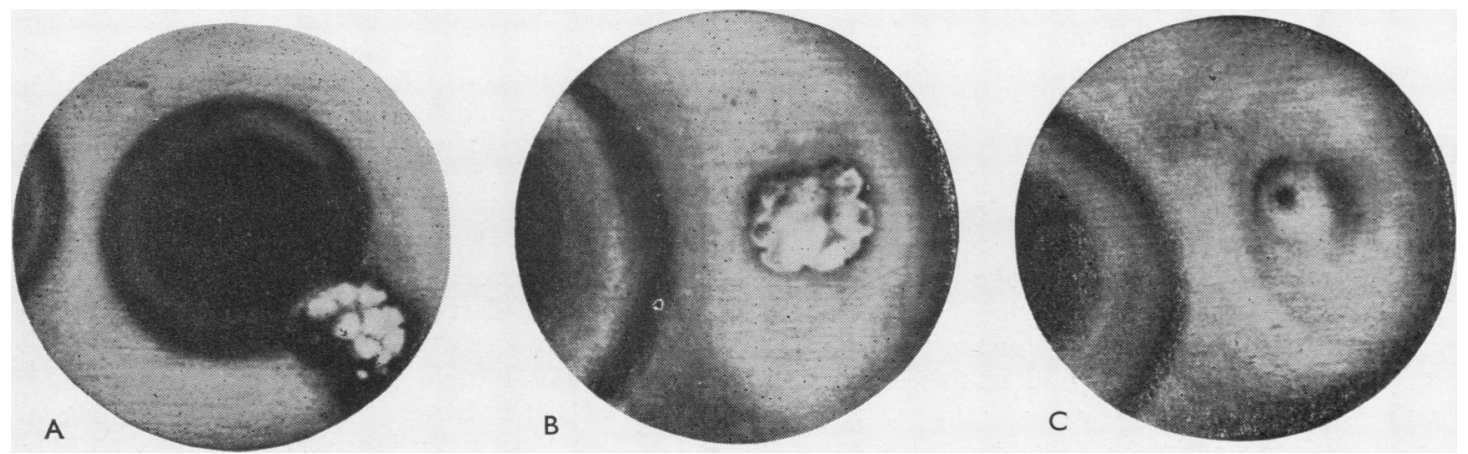

FIG. 7. Bronchoscopic course of a stenotic tuberculous bronchial lesion leading to a 'destroyed lung'. (A) 25 January 1951, large, vegetating ulcer at the lower end of the right wall of the trachea invading the right main bronchus; (B) 30 October 1951, large ulceration covered by vegetations and bits of caseum, completely obstructing the right main bronchus; (C) 13 December 1951, right main bronchus reduced to a pin-point. 


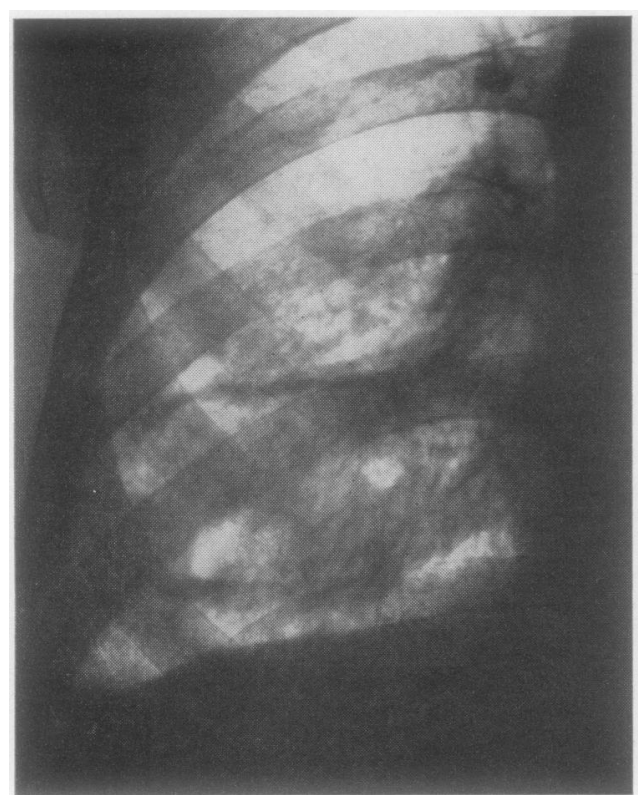

FIG. 8. A.D.D. Chest radiograph on admission, showing a large, thin-walled cavity in the right lower lobe.

under 12 years old. The following changes were found at bronchoscopy: bronchial ulcers, 12 ; ulcerated granulomas, 4 ; plaques of haemorrhagic bronchitis, 2 ; and recent scars of the bronchial wall with their accompanying varices and other local circulatory changes, 11 . In another 27 patients haemoptyses were originated by calcified lymph nodes and again only two of the patients were children. Haemorrhagic bronchitis directly related to the calcified node was the dominant bronchoscopic picture and was seen in 13 patients. Ulcers were seen in six patients, organized stenosis in three, and localized scars in five. In this group the severity of the haemoptyses necessitated lobectomy in two patients.

BRONCHOLITHS Calcified lymph nodes were seen coming through the bronchial wall in eight patients, all except one in adults. In all these patients haemoptysis was the reason for the revealing bronchoscopy. In two patients the bleeding was so severe that a lobectomy had to be performed. The patient we now report is of interest as being the only child in this series.

I. M. N.P., a 4-year-old girl, had had a primary tuberculous infection in the right hilum at the age of 2 for which she was treated in hospital. In September 1961 the child was admitted to the paediatric department of the Lisbon University Hospital as an emer- gency because of abundant haemoptysis. A chest radiograph on admission (Fig. 9) showed an opacity of the middle lobe in which a mulberry-like calcification was visible. The right upper interlobar lymph node was also calcified. Bronchoscopy showed, on the antero-lateral aspect of the lower end of the right main bronchus, a white mulberry-shaped mass embedded in bright red bleeding mucosa. A biopsy gave the sensation of biting a stone, and histology of this specimen showed calcified masses and many neutrophils. Bronchography at this time showed

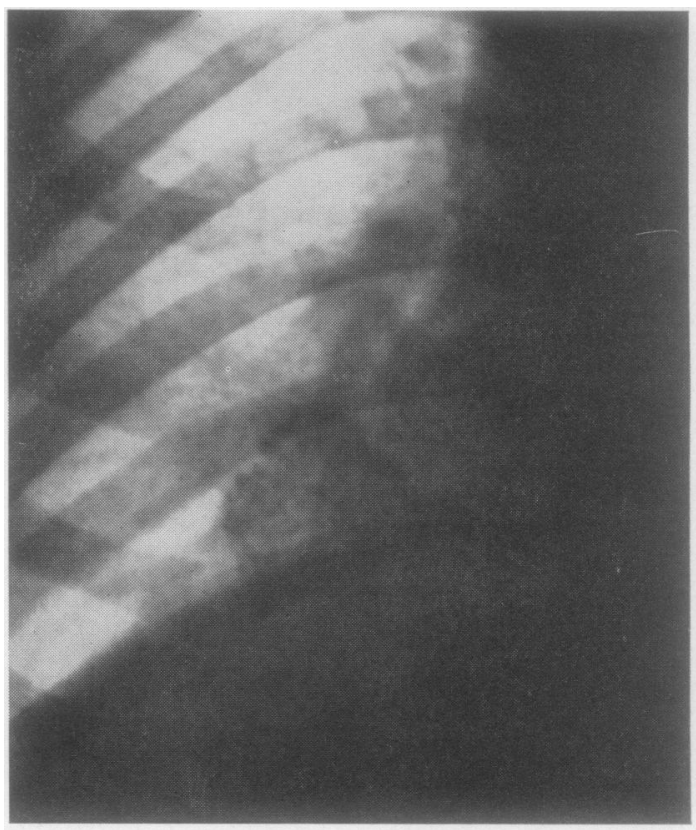

FIG. 9. I.M.N.P. Chest radiograph on admission, showing collapse of the middle lobe with a large calcified mass within it and a calcified hilar lymph node.

clumping of the branches of the middle lobe bronchus (Fig. 10) and a small lacunar image in the main bronchus right above the middle lobe bronchus. In October 1961 a middle lobe lobectomy was done and a large, partially calcified tuberculoma was found in the resected lobe.

UNEXPLAINED FEVER SYNDROMES Reactivated tuberculous tracheobronchial lymph nodes are not generally considered in the differential diagnosis of unexplained febrile syndromes.

Since 1959 I have been studying this type of patient at the Infectious Diseases Department of the Lisbon University Hospital (David and Villar, 1960), and in approximately 300 of these patients admitted since then the syndrome appeared to be related to the reactivation of tuberculous 
mediastinal glands in 81 , in six of whom the offending lymph node was partially calcified. All these patients had routine tests for brucellosis, salmonellosis, malaria, and other more usual causes of fever. In studying the problem of mediastinal lymph nodes, chest radiographs in P.A. and lateral views were taken routinely, and occasionally tomograms of the same projections. All patients had a routine bronchoscopy, and bronchial lesions were found in 55: extrinsic compression in six, infiltration in two, ulcers in 31 , granulomas in seven, areas of haemorrhagic bronchitis in two, organized stenosis in one, and scars of the bronchial wall in six. The ages of these patients varied from 6 to 67 years, average 22 years, and there were twice as many men as women in the series. Although the standard P.A. film of the chest was usually read as negative, the lateral view showed enlarged mediastinal lymph nodes in a high proportion of patients, and these were seen on the tomogram in the remainder. I was impressed by the high percentage $(68 \%)$ in whom bronchial changes were found at bronchoscopy in this series, as it was much higher than that found at routine bronchoscopy in unselected tuberculous patients $(25 \%)$. In 10 patients tubercle bacilli were found in bronchoscopically collected secretions. All

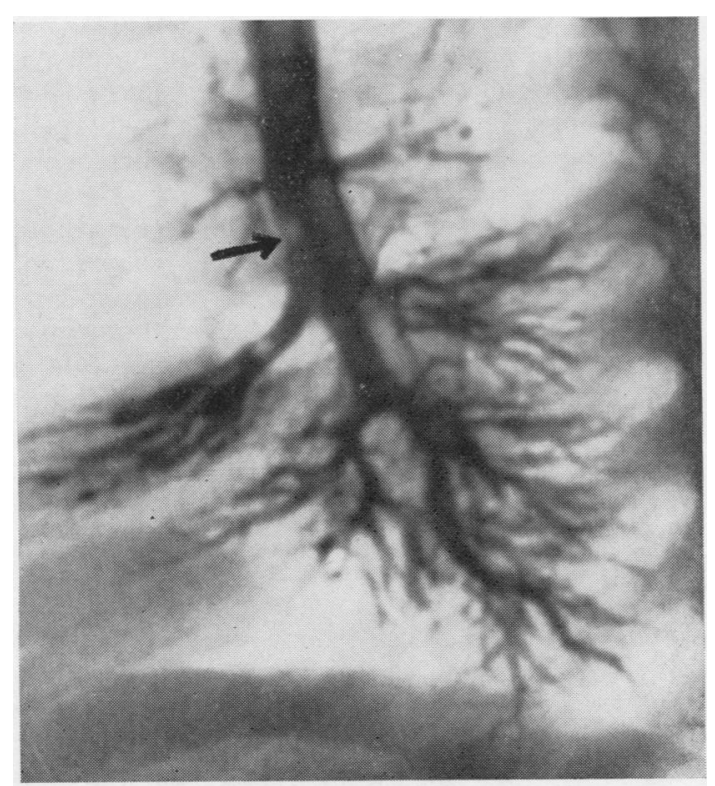

FIG. 10. I.M.N.P. Bronchogram with clumping of the branches of the middle lobe bronchus and a lacunar image in the main bronchus corresponding to the broncholith (arrow). patients in this series were submitted to a trial treatment with antituberculous drugs and all responded satisfactorily.

UNEXPLAINED POSITIVE SPUTUM Tubercle bacilli were found in the sputum of 17 patients whose chest films were either read as negative or showed residual pulmonary lesions that would not be expected to produce tubercle bacilli. Fifteen of these patients were adults and two were children, and the bronchial lesions found were related to calcified lymph nodes in four. At bronchoscopy the following lesions were found: extrinsic compression in one, a haemorrhagic bronchitis in one, ulcers in 12, granulomas in two, and a bronchial scar in one. Lobectomy was done in a 9-year-old boy who had an ulcero-stenosis that dated back to primary infection at the age of 6 months.

SCAR CANCERS (Schwartz, 1956) Adenocarcinoma developed on a scar in the bronchial wall closely related to a calcified lymph node in a 46-year-old man. In another man, 45 years old, a tuberculous lymph node broke through into the bronchus, and he had tubercle bacilli in bronchoscopically collected secretions. He was followed up and had a residual bronchial scar on which a squamouscell carcinoma developed four years later. A pneumonectomy was performed in both patients.

RELATION OF TREATMENT TO RADIOLOGICAL AND BRONCHOSCOPIC CHANGES It is interesting to try to correlate the course of the pulmonary lesions as seen radiographically and the bronchial lesions followed up by bronchoscopy with the type of treatment the patient received.

For this purpose 163 patients were chosen with two definite types of radiological picture: those with lymph-node shadows, with and without bronchogenic spread ; and those with more or less localized pulmonary infiltrations. As the course might differ in children and in adults, the patients were separated into those under and those over 12 years of age. All these patients were in hospital for the greater part of their treatment, and three therapeutic regimes are considered: bed rest alone, and chemotherapy with streptomycin or with isoniazid as the basic drug.

Lymph node shadowing (a) Under 12 years old : Fifteen of the children under 12 had only lymphnode shadows on a chest radiograph: four were treated with bed rest alone and, of these, three were cured and one developed bronchiectasis; in all cases the bronchial lesions healed with no 
appreciable reduction of the bronchial lumen. Two patients were treated with streptomycin alone, and in both the radiographic shadows cleared with no appreciable reduction of the bronchial lumen. Nine other patients received isoniazid as the basic drug ; six cleared completely and three developed bronchiectasis; in the latter a cicatricial stenosis of the bronchus involved developed from what was first seen as an extrinsic compression.

In this group of children with lymph-node shadows as the only radiographic finding the different types of therapy employed do not seem to have greatly influenced the course of the disease.

The chest film showed a bronchogenic spread besides lymph-node shadowing in six children. Only one of these received streptomycin alone, and complete regression of the pulmonary pathology was seen with a small scar in the bronchial wall where a granuloma had first existed. All the other patients in this group were given isoniazid as the main drug. In two, both the pulmonary and the bronchial lesions regressed completely. In another two, bronchiectasis developed, although the bronchial lesion only healed with stenosis in one. In one patient a severe cavitating tuberculosis developed under INH treatment, and the endobronchial granuloma seen at the first examination remained unchanged all through the observation period of six months.

In this group there also seemed to be no particular difference in behaviour depending on which therapeutic regime was employed.

(b) Over 12 years old: Twenty-eight patients over 12 years of age had only lymph-node shadows on a chest radiograph. Seven were treated with bed rest alone: five completely cleared both their pulmonary and bronchial lesions, one developed bronchiectasis with positive sputum after curing an ulcer in the dependent bronchus, and the remaining patient progressed to cavitating tuberculosis from which he died. Thirteen patients, four of whom had positive sputum, were treated with streptomycin as the main drug. Twelve cleared both their pulmonary and bronchial pathology, but one, with a partially calcified gland and tubercle bacilli in the sputum, developed bronchiectasis secondary to bronchostenosis. Eight patients, three of whom had positive sputum, received INH as the main drug, and all cleared both their pulmonary and bronchial pathology with no appreciable sequelae.

In this group the patients treated with INH seem to have had a slightly more favourable course than the others. What is more striking, when compared with that seen in those under 12 years of age, is the much lower incidence of residual pulmonary pathology.

In 11 patients a bronchogenic spread was associated with the lymph-node shadows on the $\overparen{D}$ chest radiograph. Only one was treated with bed rest alone, and he cleared both pulmonary and bronchial lesions in six months. Six patients were $\vec{\circ}$ given streptomycin as the basic drug: there was $\overrightarrow{\vec{A}}$ complete regression of both pulmonary and $\stackrel{\omega}{\circ}$ bronchial lesions in three patients; two others $\overrightarrow{\overrightarrow{\vec{F}}}$ developed bronchiectasis secondary to bronchial $\stackrel{\times}{.}$ stenosis, and the remaining patient progressed to $\infty$ cavitating tuberculosis which did not respond to $\omega$ artificial pneumothorax. Isoniazid was the basic drug administered to four patients: three showed complete regression of their pulmonary and bronchial lesions and one developed bronchiectasis $\vec{c}$ and bronchostenosis.

In this group there was again no appreciable $\frac{\mathbb{T}}{\mathrm{T}}$ difference in relation to treatment.

Pulmonary infiltration (a) Under 12 years old: Thirty-nine children under 12 years of age had $\vec{\bullet}$ pulmonary consolidation on a chest film. In 10 ङ a whole lung was involved, the left in eight and the right in two. In the remainder the right upper lobe was involved in 14 patients, the middle lobe in five, the right lower lobe in five, and the left upper lobe in another five patients.

In the 10 in whom a whole lung was involved $\stackrel{\mathbb{2}}{2}$ by the consolidating process, two were treated with $\overrightarrow{\overrightarrow{0}}$ bed rest alone and both ended up with 'destroyed 3 lungs' and stenotic main bronchi. Three were treated basically with streptomycin and they also developed extensive bronchiectasis and bronchostenosis. The remaining five patients were treated $\mathrm{O}$ with INH: in one there was complete clearing of $\stackrel{0}{x}$ the pulmonary lesion, and the extrinsic compres- $\frac{0}{3}$ sion that caused the parenchymal collapse regressed with no apparent residual pathology; in three, residual bronchiectasis was found, and in all of them the bronchial lesion healed with 을 marked stenosis; in one, in whom an endo- $\rightarrow$ bronchial granuloma led to a cicatricial stenosis, a serious cavitating tuberculosis developed.

In this group, regardless of treatment, the incidence of pulmonary sequelae was very high. $N$

Five of the children with lobar consolidation $\underset{\omega}{\mathcal{N}}$ were treated with bed rest alone: in three bronchi- 0 ectasis developed in the right upper lobe, middle lobe, and right lower lobe, although the obstructive $\frac{\bar{\Phi}}{\bar{D}}$ bronchial lesions cleared up with no appreciable $\stackrel{?}{+}$ reduction in the bronchial lumen; in the other 0 two, cavitating tuberculosis developed, and the ${ }_{0}$

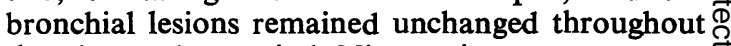
the observation period. Nine patients were treated $\overrightarrow{\mathbb{D}}$ with streptomycin as the basic drug: in one, both 
the pulmonary and bronchial lesions regressed without sequelae; four developed right upper lobe bronchiectasis, this apparently being favoured by artificial pneumothorax on two occasions as the bronchial lesions healed without bronchostenosis in all cases ; four progressed to cavitating tuberculosis on streptomycin therapy although the bronchial lesion healed in all cases with no appreciable stenosis; an artificial pneumothorax was done in three patients. Fifteen of these children with lobar consolidation were treated with isoniazid: in two, the chest radiograph cleared completely as did the bronchial lesion; 11 developed bronchiectasis (six in the right upper lobe, two in the middle lobe, and three in the right lower lobe), and in seven the bronchial lesion healed with marked reduction of the bronchial lumen; an artificial pneumothorax was done in two patients, one of whom died ; two patients with left upper lobe infiltration progressed to cavitating tuberculosis (one under artificial pneumothorax), both having healed their bronchial lesions without bronchial stenosis.

Again in this group the type of treatment does not seem greatly to have affected the outcome of the pathological progress. The unfavourable effect of collapse therapy seems evident as does the independent course of bronchial and pulmonary lesions in some cases.

(b) Over 12 years old: Pulmonary consolidation was found in 64 patients over 12 years of age, 11 involving a whole lung (three the right and eight the left) and the remainder affecting different lobes (19 right upper lobe, six middle lobe, 21 right lower lobe, six left upper lobe, and two left lower lobe).

Two of the patients with a whole lung involved were treated with bed rest alone, and both developed residual bronchiectasis secondary to bronchostenosis, one under artificial pneumothorax therapy. Six were given streptomycin as the basic drug: four (two of whom were having pneumothorax therapy) developed 'destroyed lungs' although only two had appreciable bronchostenosis; in two patients progressive pulmonary tuberculosis developed under streptomycin therapy, one with bronchial stenosis and the other under ineffective collapse therapy although there was no reduction in the bronchial lumen. Isoniazid was given to three patients, and all developed bronchiectasis secondary to bronchostenosis.

In this group one is impressed by the high incidence of residual pathology and by the apparent inefficiency of all types of treatment.

Of the 53 patients with lobar consolidation, 13 received no chemotherapy; three cleared up even though one was treated with artificial pneumo- thorax and another developed a bronchial stenosis ; three developed lobar bronchiectasis (secondary to an irreversible bronchial stricture only once); seven went on to progressive tuberculosis, and in two of these the pneumothorax was completely ineffective, although only two had obstructive endobronchial granulomas up to the end of the observation period. Twenty-one patients were treated basically with streptomycin; five cleared both their pulmonary and bronchial lesions, one of them whilst under artificial pneumothorax ; 10 developed bronchiectasis, although in five the bronchial lesions healed with no appreciable stricture; six patients developed progressive cavitating tuberculosis, only two with bronchostenosis; pneumothorax, phrenic nerve crush, and thoracoplasty were done in four patients with unfavourable results. Isoniazid was the main drug given to 19 patients: eight cleared their parenchymal lesions, although four had residual bronchial lesions which considerably reduced the bronchial lumen; five developed lobar bronchiectasis (three secondary to residual bronchial stenosis); six patients progressed to cavitating tuberculosis although only one had a cicatricial bronchostenosis. Pneumothorax, phrenicectomy, and thoracoplasty were ineffective in four of these patients.

Again the high incidence of residual pathology is impressive in this group as is the fact that the different types of treatment did not significantly affect the course of the disease. All collapse measures led to unfavourable results.

Analysing the data from the 163 patients just reviewed as a whole, we agree with Bentley, Grzybowski, and Benjamin (1954) and with Macpherson et al. (1960) that, once the lymph-node and bronchial tuberculous process is started, it is scarcely influenced by the type of treatment administered to the patient. However, there seems to be a slight improvement in results when isoniazid is used as the basic drug.

The nature of these pulmonary consolidations, so often associated with mediastinal lymph-node tuberculosis both in children and in adults, has been the subject of much discussion from the time of Eliasberg and Neuland (1920) with their 'epituberculosis' and Rössle (1935) with his 'pure' and 'impure' atelectasis. While some think that these pulmonary consolidations are mostly due to simple absorption collapse (Macpherson et al., 1960 ; Brock, Cann, and Dickinson, 1937) others believe they generally correspond to specific or non-specific pneumonias.

I think that, as the bronchial obstruction generally takes place gradually, a certain amount 
of usually low-grade infection always develops beyond it. When infective material from the ruptured tuberculous lymph node seeds the collapsed area of the lung, tuberculous foci may develop within it.

In our 23 resected specimens, pure collapse as described by Lynne Reid (Macpherson et al., 1960) was never found. Our material is more like that described by Sully Hospital's pathologist (Seal, 1958). In all our cases chronic interstitial pneumonia existed with more or less extensive fibrosis. In 12, definite bronchopulmonary suppuration was found; and in three, active tuberculous foci could be demonstrated in the areas of infiltration. The frequency with which these areas are seeded with tuberculosis also seems to be brought out by the high incidence of progressive tuberculosis that developed in our series $(30 \%)$. Even in patients in whom the infiltration cleared up I believe that, should their lungs be examined histologically, residual signs of specific or nonspecific infection would be found.

\section{SUMMARY AND CONCLUSIONS}

An analysis of the clinical, radiological, and bronchoscopic data collected from 4,982 tuberculous patients, ranging in age from 2 months to 68 years, is used to assess the early and late effects of the lymph-node component of primary tuberculous infection on the tracheobronchial tree and on bronchopulmonary pathology in patients of all ages.

A high percentage (14\%) of tuberculous lesions found in the bronchi of tuberculous patients are related to the tuberculous process in the tracheobronchial lymph nodes and so can be related back to the primary infection.

The younger the child at the time of primary infection, the greater are the chances of irreversible changes developing in the bronchial tree. Approximately half the bronchial lesions of serious primary infection leave important residual pathology. The course of the pulmonary and bronchial lesions does not appear to be greatly influenced by the type of treatment administered.

Residual tuberculous processes in the tracheobronchial lymph nodes and the related bronchial changes can cause distressing syndromes and extensive damage to the lungs both during the active phase of the tuberculous process and later.
Bronchial lesions due to tuberculous lymph nodes led to pulmonary resection in 33 of the 378 patients $(9 \%)$ who were followed up for a sufficient time. However, six of these patients on whom pulmonary resection was done developed bronchial fistulae $(18 \%)$. Twenty other patients of this series were submitted to other forms of major chest surgery ( $5 \%$ ), and 25 were advised to undergo surgery and refused it $(6.6 \%)$. Also, 19 patients in this series died from their disease, bringing the mortality in this group up to $5 \%$.

From these data it seems clear that primary tuberculous infection should be avoided at all costs by the correct and intensive use of current prophylactic measures. Once established, primary infection should be treated as early as possible with the appropriate drugs, in correct doses and for sufficient periods of time to try to avoid bronchial lymph-node lesions which, as I have shown, are not greatly influenced by any type of therapy. The use of corticosteroids may have to be considered, but my personal experience is too small to be definite about their usefulness. We should always be alert to determine the exact moment when a surgical intervention on an offending lymph node, adenotomy or adenectomy (Thomas, 1952 ; Giraud and Métras, 1953), can avoid more extensive and mutilating surgery later on.

\section{REFERENCES}

Bentley, F. J., Grzybowski, S., and Benjamin, B. (1954). Tuberculosis in Childhood and Adolescence. N.A.P.T., London.

Brock, R. C., Cann, R. J., and Dickinson, J. R. (1937). Tuberculous mediastinal lymphadenitis in childhood; secondary effects on the lungs. Guy's Hosp. Rep., 87, 295.

David, A. M., and Villar, T. G. (1960). Sindroma febril agudo como manifestação de adenopatia traqueo-brônquica tuberculosa, no adulto. Gaz. méd. port., 13, 723 .

Eliasberg, $\dot{H}$., and Neuland, W. (1920). Die epituberkulöse Infiltration der Lunge bei tuberkulösen Säuglingen und Kindern. Jb. Kinderheilk., 93, 88 .

Giraud, P., and Métras, H. (1953). L'exérèse ganglionnaire et la désobstruction bronchique dans certaines formes compliquées de la primo-infection. Rev. Tuberc. (Paris), 5 ser., 17, 437.

Macpherson, A. M. C., Zorab, P. A., and Reid, L. (1960). Collapse of the lung associated with primary tuberculosis: A review of 0 51 cases. Thorax, 15, 346.

Rössle, R. (1935). Die pathologisch-anatomischen Grundlagen der $D$ Epituberkulose. Virchows Arch. path. Anat., 296, 1.

Schwartz, Ph. (1948). Die anatomische, endogene, lymphadeno- 음 bronchogene Reinfektion in der Initialperiode der Tuberkulose. bronchogene Reinfektion in der Initialperiode der Tuberkulose. $\mathrm{N}$
Folia Pathologica, I. Méd., 57, 533 .

Seal, R. M. E. (1958). The pathology of pulmonary tuberculosis. Brit. J. clin. Pract., 12, 769.

Thomas, D. (1952). The fate of the tuberculous primary complex. $\omega$

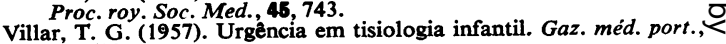

10, 633. Prognóstico da Tuberculose Pulmonar. Gomes e Rodrigues Edit., $\mathbb{D}$ Lisboa. 